\title{
Model Analysis of Energy Network System in Zero Emission Industrial Park*
}

\author{
Yoichi SHIMAZAKI**
}

\begin{abstract}
The aim of this study was to evaluate energy saving in cases of introducing both a cogeneration system and an energy network in Kokubo Industrial Park. The industrial park has implemented zero emission activities since 1992. The energy data of 22 factories were classified into steam, hot water, heating, cooling and electric power on the basis of interviews. The author developed an energy network model based on linear programming, so as to minimize the total system cost. The industrial park was divided into a 10,000 square meter mesh in order to take steam transport into consideration. Three cases were investigated. The ratio of energy saving to demand reached $22 \%$ compared with the reference system. It was found that the energy network system could correspond to the energy demand seasonally. This is useful for the stable supply of energy, prevention of air pollution, and improvement of urban design.
\end{abstract}

Key Words: Energy Saving, Gas Turbine, Heat Transfer, Combined Heat and Power, Linear Programming

\section{Introduction}

Energy security issues are more critical for Japan than for most other countries, because of its geographical location and limited domestic energy resources. Oil accounts for over 50\% of Japan's primary energy supply. Consequently, Japan is making great efforts to ensure security of supply. Now, oil demand has soared in Brazil, Russia, China and India (BRICs). The rise in oil prices has driven the market's upward surge worldwide. Moreover, according to the Kyoto Protocol, drawn up in December 1997, Japan has assumed an international obligation to reduce the amount of greenhouse gas emissions, such as carbon dioxide, by 6\% from 2008 to 2012, compared with $1990^{(1)}$.

Energy saving is one of the effective ways of reducing greenhouse gases. One obvious example of energy saving is the use of combined heat and power (CHP). CHP, also known as cogeneration system, is an efficient, clean, and reliable approach to generating power and thermal energy form a single fuel source. In 1997, The Law for Promotion of the Utilization of New Energy was enacted in Japan. A

* Received 4th October, 2005 (No. 05-4203)

** Social System Engineering, Division of Engineering, Interdisciplinary Graduate School of Medicine and Engineering, University of Yamanashi, 4-3-11 Takeda, Kofu, Yamanashi 400-8511, Japan.

E-mail: simazaki@yamanashi.ac.jp natural gas cogeneration system appears to be the most promising option for the near future. Natural gas is favorable as a source of energy for a number of reasons. It is not a resource concentrated in the Middle East, from a security viewpoint. Furthermore, it is less of a burden on the environment compared with other fossil fuels. There is also a possibility that it can be used in new forms of energy such as gas to liquid (GTL) and dimethyl ether (DME). Therefore, it is a very important energy source. In 2004, the Japanese government imposed the "Renewable Portfolio Standard" to obligate electric power companies to use a specific amount of new energy ${ }^{(2)}$. Along with liberalization and intensifying competition over recent years, the energy industry in Japan is undergoing a period of dramatic change. For example, the microgrid cogeneration system presented at the 2005 World Exposition in Aichi Prefecture reduced pavilion energy consumption. The microgrid project, fueled by hydrogen and natural gas, will include the use of several emerging on-site energy technologies. The microgrid will also include underground electrical and thermal distribution systems to provide electricity, heating and air conditioning to next-generation energy facilities ${ }^{(3)}$.

In this study, the author investigated the energy saving potential of Kokubo Industrial Park in Yamanashi Prefecture, located $110 \mathrm{~km}$ west of Tokyo. It is the largest industrial park in Yamanashi Prefecture. Natural gas supplies increased in 2003 as a result of the extension of the 
Kofu pipeline. In particular, the location is close to the route of the pipeline. There is little literature available on the analysis of the introduction of a cogeneration system to the entire industrial park. Bruckner et al. introduced a dynamic energy optimization model for the cogeneration system. The model was applied in an actual city in Germany ${ }^{(4)}$. However, the concept of the energy network has not been taken into account in the literature. Ishizaka et al. calculated the energy saving potential in an actual city using mesh data in order to take waste heat transport into consideration $^{(5)}$. However, the model does not include the industrial sector. Shimazaki developed an energy network model based on linear programming, so as to minimize the total fuel consumption in Kokubo Industrial Park ${ }^{(6)}$. The author expanded this model not only to the total system cost but also the location of the factory. In this paper, the author described the Kofu Line, zero emission activities, model structure, simulation cases, optimization results of the energy network model and conclusions. The simulation results suggest that the adoption of an energy network can effectively reduce fuel consumption. It is an effective measure for the industrial park to introduce natural gas cogeneration systems.

\section{Nomenclature}

Variables

$B$ : boiler output

$E:$ electric power transport

$G E$ : gas engine output

$G T$ : gas turbine output

$J$ : system cost

$K:$ installed capacity

$Q:$ steam transport capacity

$U T:$ utility output

Parameters

$c:$ cost

$d:$ days (summer122, winter 121 , other122)

$r:$ average annual cost rate $(0.169)$

$s:$ distance to factory

$\eta$ : efficiency (B 0.85, UT 0.38, GE 0.35, GT 0.25)

Superscripts

$a$ : other factories (21)

gas : city gas

$i:$ factory (22)

$j$ : season (3)

$k:$ hours (24)

oil : heavy oil

$t:$ energy conversion technology (12) $u t:$ utility

\section{Energy Network Model}

\subsection{Kofu Line}

Figure 1 shows the Kofu Line on a pipeline map. In 1959, Teikoku Oil discovered a new natural gas field in

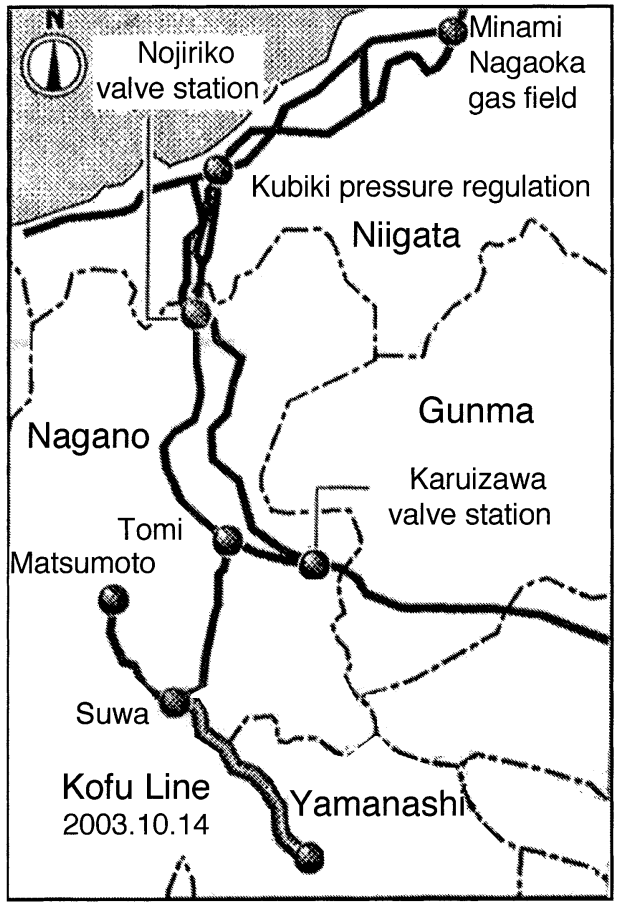

Fig. 1 Kofu Line on a pipeline map

Niigata Prefecture. The Tokyo Line, built in 1962, was activated from Niigata to Tokyo with a total length of $310 \mathrm{~km}$. In addition, the Minami-Nagaoka gas field was discovered in 1979. This gas field has reserves of a domestic maximum level at the core of their business. In the past several years, the company has pursued a rigorous program of new pipeline construction. They completed the New Tokyo Line in 2000, the Matsumoto Line in 2002 and the Kofu Line in 2003. The company decided to complement its gas supply capabilities by purchasing Liquid Natural Gas (LNG). In conjunction with this decision, they will build two more natural gas pipelines: the Shizuoka Line and the Minami-Fuji Line. Once these lines are completed, their pipeline network will represent Japan's largest high-pressure natural gas transport system, with a total length of $1,200 \mathrm{~km}$. That network will supply domestically produced natural gas from the Sea of Japan and LNG-vaporized gas from the Pacific Coast at the same time. The result will be a dramatic improvement in the supply stability of our entire network, in both qualitative and quantitative terms ${ }^{(7)}$.

\subsection{Zero emission industrial park}

Kokubo Industrial Park is situated on a 956,000 square meter site housing 24 companies and about 5,500 employees. The companies consist mainly of electronic products and parts manufacturers, including Yokogawa Electronics, Panasonic, Fujitsu and Pioneer. In Japan, industrial waste management falls under the jurisdiction of the prefectural government. Since this project is located in Yamanashi Prefecture, where there is no industrial waste treatment facility, all park-generated waste initially had to 
be transported and treated in another prefecture. The concept of zero emission started taking shape when a member of the cooperative raised the idea of incorporating waste disposal into environmental elements. Since beginning zero emissions activities in 1992, the consortium has already implemented the following four steps.

Step 1: Centralized system for recycling paper, used by 23 companies.

Step 2: Centralized system for recycling waste plastic, wood chips, etc.

Step 3: Recycling of food waste from staff canteens into compost.

Step 4: Fabrication of pulp molds from used paper.

The Kokubo project is unique in that it is entirely selfevolving and self-managed. The government has played no direct role in the development of this park. It is a result of the initiative of a group of factories, driven by their desire to reduce costs and improve environmental performance. The project was clearly the result of a management program to obtain an economic advantage while putting into action their concern for the environment. Furthermore, the cost advantages are largely a result of increased stress on resources and the environment in the region, as well as tightened environmental regulations. In 2004, 11 companies obtained ISO14001 Environmental Management Systems. By working hand in hand with local universities and authorities, the consortium will expand its activities to the entire prefecture ${ }^{(8),(9)}$.

\subsection{Model structure}

Table 1 shows the energy use of the 22 factories in this study. The energy data was classified into steam, hot water, heating, cooling and electric power on the bases of interviews. It can be seen that there are various scales of factory from the viewpoint of the amount of peak demand etc. Table 2 shows the parameters of energy conversion technologies ${ }^{(10)}$. Figure 2 shows a scheme of the energy network model in which the above technology is integrated. There are two types cogeneration systems: gas turbine (GT) and gas engine (GE). The differences between the two facilities are electric power generation efficiency, heat efficiency, and waste heat temperature. Although the generating efficiency of a gas turbine is lower than that of a gas engine, the waste heat temperature is higher. It is possible for a double-effect absorption chiller (DAR) to fulfill the cooling demand of a steam source, e.g., waste heat generated by gas turbine. The industrial park was divided into a 10,000 square meter mesh, that is 14 times 9 grids to take steam transport into consideration. In this model, the steam pipeline cost is proportional to both the pipeline length and the steam flow, according to the steam pipework diagram ${ }^{(11),(12)}$. The steam transport is limited to waste heat from gas turbine cogeneration.

The author has developed an energy network model based on linear programming, so as to minimize the total

Table 1 Energy use in 22 factories

\begin{tabular}{|c|c|c|c|c|c|c|}
\hline factory & $\begin{array}{c}\text { peak demand } \\
{[\mathrm{kW}]}\end{array}$ & $\begin{array}{l}\text { load factor } \\
{[\%]}\end{array}$ & $\begin{array}{l}\text { thermoelectric } \\
\text { ratio[-] }\end{array}$ & $\begin{array}{l}\text { steam demand } \\
\text { utilization[\%] }\end{array}$ & $\begin{array}{l}\text { heating demand } \\
\text { utilization }[\%]\end{array}$ & $\begin{array}{c}\text { cooling demand } \\
\text { utilization }[\%]\end{array}$ \\
\hline $\mathrm{A}$ & 2,652 & 58.2 & 1.7 & 1.2 & 4.7 & 56.9 \\
\hline $\mathrm{B}$ & 2,549 & 77.9 & 2.0 & 13.6 & 1.5 & 51.6 \\
\hline $\mathrm{C}$ & 715 & 74.7 & 2.6 & 15.9 & 11.3 & 44.9 \\
\hline $\mathrm{D}$ & 2,248 & 49.5 & 2.6 & 47.5 & 6.1 & 16.7 \\
\hline $\mathrm{E}$ & 1,150 & 54.9 & 2.6 & 0.0 & 22.3 & 48.7 \\
\hline $\mathrm{F}$ & 58 & 35.7 & 0.3 & 0.0 & 20.8 & 2.5 \\
\hline G & 219 & 29.3 & 0.1 & 0.0 & 8.5 & 2.0 \\
\hline $\mathrm{H}$ & 5,516 & 85.7 & 3.3 & 27.7 & 2.4 & 46.7 \\
\hline I & 1,938 & 60.7 & 1.4 & 0.0 & 16.9 & 41.0 \\
\hline $\mathrm{J}$ & 2,404 & 78.3 & 1.4 & 37.8 & 2.9 & 18.1 \\
\hline $\mathrm{K}$ & 752 & 42.0 & 0.6 & 0.0 & 18.6 & 17.5 \\
\hline $\mathrm{L}$ & 2,691 & 75.5 & 2.0 & 46.9 & 3.1 & 17.1 \\
\hline M & 229 & 39.3 & 1.8 & 11.2 & 21.0 & 12.9 \\
\hline $\mathrm{N}$ & 602 & 30.2 & 3.7 & 63.8 & 13.4 & 1.3 \\
\hline $\mathrm{O}$ & 101 & 64.6 & 5.6 & 0.0 & 14.7 & 70.0 \\
\hline $\mathrm{P}$ & 279 & 26.1 & 0.6 & 0.0 & 18.3 & 18.3 \\
\hline Q & 433 & 46.3 & 0.5 & 0.0 & 19.3 & 13.2 \\
\hline $\mathrm{R}$ & 255 & 33.5 & 0.6 & 0.0 & 16.6 & 20.8 \\
\hline S & 403 & 76.7 & 8.3 & 48.7 & 0.0 & 40.5 \\
\hline $\mathrm{T}$ & 65 & 35.7 & 0.0 & 0.0 & 0.0 & 0.0 \\
\hline $\mathrm{U}$ & 258 & 32.5 & 1.3 & 0.0 & 19.6 & 35.7 \\
\hline V & 1,077 & 31.9 & 0.3 & 0.0 & 18.3 & 3.9 \\
\hline \multicolumn{7}{|c|}{ Peak demand is defined as the maximum electric power demand in one year. } \\
\hline \multirow{2}{*}{\multicolumn{7}{|c|}{$\begin{array}{l}\text { Load factor is defined as the quotient of the average electric power demand and the maximum electric power demand. } \\
\text { Thermoelectric ratio is defined as quotient of total heat demand and total electric power demand. }\end{array}$}} \\
\hline & & & & & & \\
\hline \multicolumn{7}{|c|}{ Steam demand utilization is defined as the ratio of steam demand to total energy demand. } \\
\hline \multicolumn{7}{|c|}{ Heating demand utilization is defined as the ratio of heating demand to total energy demand. } \\
\hline & & & & & & \\
\hline
\end{tabular}


Table 2 Parameters of energy conversion technologies

\begin{tabular}{|c|c|c|c|c|c|c|}
\hline Energy conversion & Symbols & Facilities a) & $\begin{array}{c}\text { Cost } \\
{[¥ / \mathrm{kW}]}\end{array}$ & $\begin{array}{c}\text { Power } \\
\text { efficiency }\end{array}$ & $\begin{array}{c}\text { Heat } \\
\text { efficiency }\end{array}$ & $\mathrm{COP}$ \\
\hline \multirow[t]{3}{*}{ Generator } & UT & power plant b) & - & 0.38 & - & - \\
\hline & GE & gas engine c) & 150,000 & 0.35 & 0.35 & - \\
\hline & GT & gas turbine c) & 150,000 & 0.25 & 0.50 & - \\
\hline \multirow[t]{2}{*}{ Heat supply } & $\mathrm{B}$ & boiler d) & 6,000 & - & 0.85 & - \\
\hline & EHP & electric power driven heat pump & 56,000 & - & - & 4.00 \\
\hline \multirow[t]{4}{*}{ Cooling supply } & CTR & electric power driven chiller & 27,000 & - & 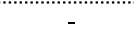 & 4.00 \\
\hline & SAR & single-effect absorption chiller & 35,000 & - & - & 0.80 \\
\hline & DAR & double-effect absorption chiller & 32,000 & - & - & 1.20 \\
\hline & TAR & three-stage adsorption chiller & 71,000 & - & - & 0.20 \\
\hline Electric storage & BAT & accumulator & 600,000 & - & - & 0.70 \\
\hline \multirow[t]{3}{*}{ Heat storage } & HAC & steam storage tank & 12,000 & - & - & 0.95 \\
\hline & MAC & hot water storage tank & 8,000 & - & - & 0.90 \\
\hline & LAC & cooling storage tank & 8,000 & - & - & 0.90 \\
\hline Electric transport & EIN & distribution line e) & - & - & - & 0.98 \\
\hline Steam transport & QIN & steam pipeline f) & - & - & 0.996 per 1 & meter \\
\hline
\end{tabular}

a) average annual cost rate $0.169[-]$, b) $1,175[¥ / \mathrm{kW} /$ month], summer $10.19[¥ / \mathrm{kWh}]$, other $9.26[¥ / \mathrm{kWh}]$,

c) city gas price $35.0\left[¥ / \mathrm{m}^{3}\right]$, d) oil price $30.0[¥ / \mathrm{L}]$, e) wheeling cost $2.87[¥ / \mathrm{kW}]$, f) pipeline cost $30.76[¥ / \mathrm{m} / \mathrm{kWh}]$

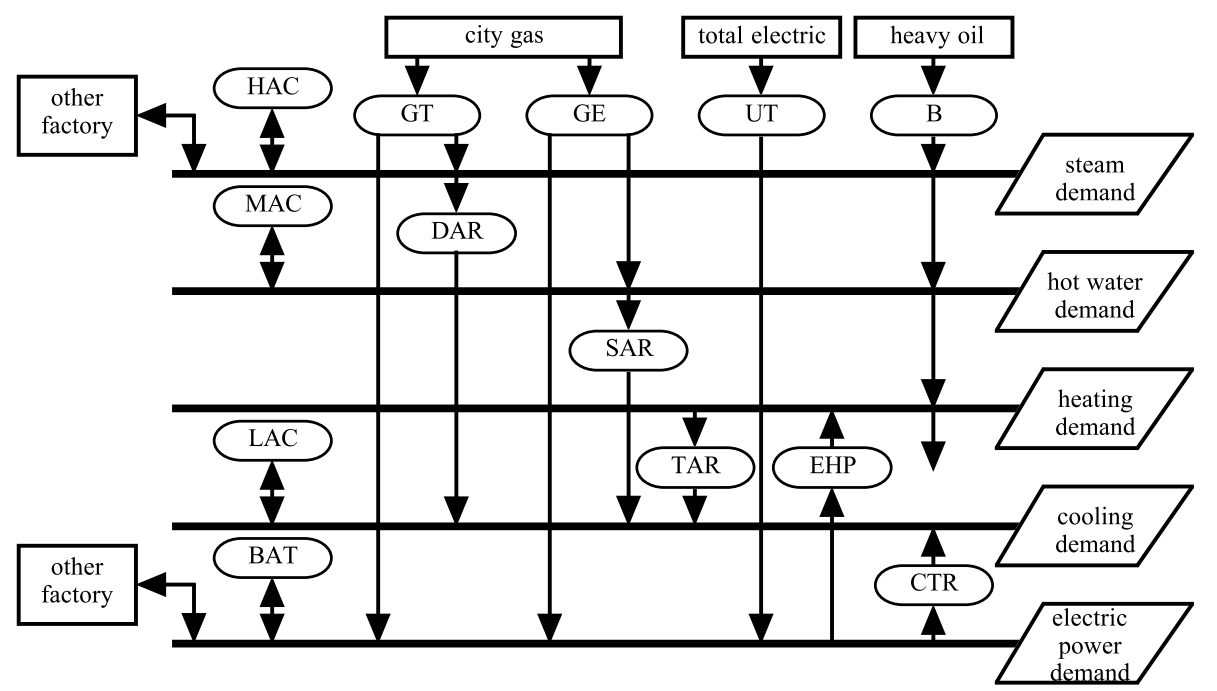

Fig. 2 Schematic diagram of the energy network model

system cost. Equation (1) shows the objective function. This is defined by the sum of fuel cost, plant cost, wheeling cost and heat pipeline cost. Total system cost minimization becomes an evaluation criterion under the constraints of energy demand and supply balance, energy storage input and output balance, transport of electric power balance, transport of steam balance, and installed capacity balance. Independent variables are energy conversion technologies output, installed capacity and energy network amount. The simulation period is one year, i.e., 3 seasons times 24 hours, without considering replacement of the facility, i.e., static model.

$$
\begin{gathered}
J=J_{\text {fuel }}+J_{\text {plant }}+J_{\text {wheeling }}+J_{\text {pipeline }} \rightarrow \text { Min } \\
J_{\text {fuel }}=\sum_{i=1}^{22} \sum_{j=1}^{3} \sum_{k=1}^{24}\left\{d _ { j } \left(\frac{B_{i j k}}{\eta_{B}} c_{\text {oil }}+\frac{U T_{i j k}}{\eta_{U T}} c_{u t}\right.\right. \\
\left.\left.+\left(\frac{G E_{i j k}}{\eta_{G E}}+\frac{G T_{i j k}}{\eta_{G T}}\right) c_{\text {gas }}\right)\right\}
\end{gathered}
$$

$$
\begin{aligned}
& J_{\text {plant }}=\sum_{i=1}^{22} \sum_{t=1}^{12}\left(c_{t} r_{t} K_{i t}\right) \\
& J_{\text {wheeling }}=\sum_{a=1}^{21} \sum_{i=1}^{22} \sum_{j=1}^{3} \sum_{k=1}^{24}\left(d_{j} c_{\text {wheeling }} E_{\text {aijk }}\right) \\
& J_{\text {pipeline }}=\sum_{a=1}^{21} \sum_{i=1}^{22}\left(c_{\text {pipeline }} r_{\text {pipeline }} S_{a i} Q_{a i}\right)
\end{aligned}
$$

\section{Optimization}

\subsection{Calculation cases}

Three cases were investigated. Energy systems of the calculation cases were as follows. Case 1 covers heating demand by a boiler, cooling demand by an electric power driven chiller, and electric power demand in the power purchased from the power plant. In Case 2, each industry was designed to have all energy conversion technologies individually. In Case 3, the energy demand and supply of each factory were connected by wheeling and steam trans- 
port. The author calculated the energy network model using General Algebraic Modeling Systems (GAMS) ${ }^{(13)}$.

Case 1: power plant, boiler, electric power driven chiller (reference system)

Case 2: In addition to Case 1, gas engine, gas turbine, waste heat driven chiller, heat pump, and energy storage

Case 3: In addition to Case 2, both electric power network and heat network between each factory

\subsection{Energy saving potential}

Figure 3 shows the optimum behavior of the total systems cost. Total cost saving reaches $21.4 \%$ and $21.8 \%$ compared with the reference system. Figure 4 shows the reduction of total fuel consumption. The fuel consumption of the electric power and boiler decrease, while the fuel consumption of gas turbine increases. Therefore, energy saving is $19.2 \%$ and $22.1 \%$ compared with the reference system. It was found that the introduction of gas turbine cogeneration is more effective than gas engine cogeneration from the viewpoint of the energy network, since there is a high steam demand in Kokubo Industrial Park. Figure 5 shows the results of energy saving for each factory for Case 2 compared with that in Case 1, the reference system. It was found that factory $\mathrm{H}$ exhibited the largest energy saving and total energy saving rate of about $7 \%$. This is one-third of the total system saving rate. Finally, the total energy saving rate was achieved by about 10 fac-

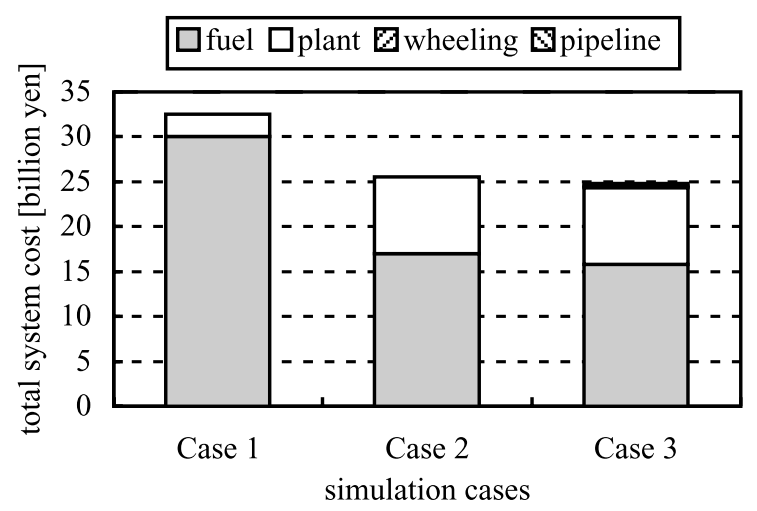

Fig. 3 Reduction of total system cost

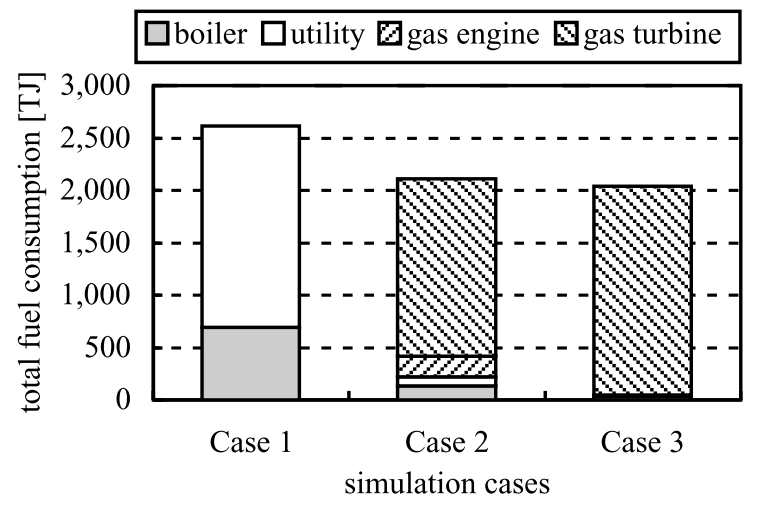

Fig. 4 Reduction of total fuel consumption tories. In other words, the introduction of the gas turbine was effective for these 10 factories. As for the energy demand characteristic of factories $\mathrm{H}, \mathrm{L}, \mathrm{J}, \mathrm{B}$ and $\mathrm{D}$, peak demand is larger than $2,000 \mathrm{~kW}$ and steam demand utilization is more than $10 \%$ as shown in Table 1. Figure 6 shows the result of energy saving for each factory in Case 3 compared with those in Case 2. The fuel consumption of factories $\mathrm{J}$ and $\mathrm{V}$ increase while the those of factories $\mathrm{H}, \mathrm{L}, \mathrm{D}, \mathrm{S}$ and $\mathrm{N}$ decrease. Because gas turbine is more excessively introduced into factories $\mathrm{J}$ and $\mathrm{V}$ in Case 3 than those in Case 2, and energy network to those factories. Thermoelectric-ratios for factories $\mathrm{J}$ and $\mathrm{V}$ are low, 1.4 and 0.3 , respectively. It is difficult to introduce gas turbines at each factory in Case 2. In addition, total fuel consumption in the only-steam-transport case is reduced compared with the only-wheeling case using optimization. Consequently, it was found that the steam network is more effective than the electric power network in Kokubo Industrial Park. Moreover, there is a slight variation in energy saving for factories B and A because their location places is the edge of the industrial park.

\subsection{Energy network}

Figure 7 shows the change of the steam network over three seasons. The thickness of the arrow shows the amount of steam transport. In winter season, gas turbine waste heat is used to satisfy the heating demand at the fac-

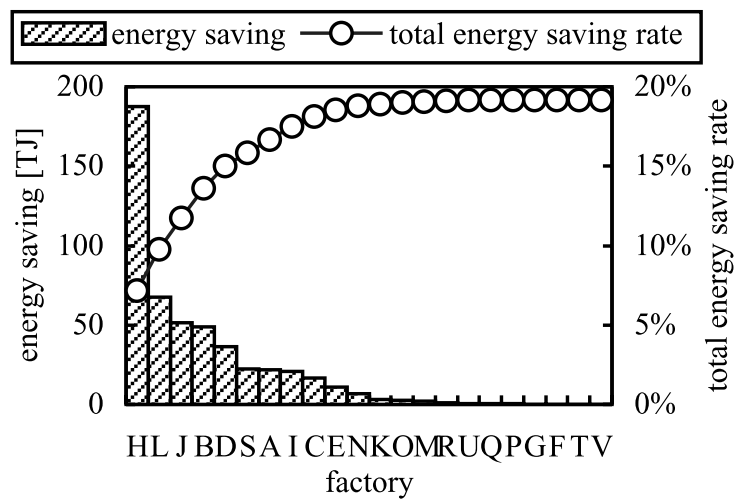

Fig. 5 Variation of energy saving in Case 2

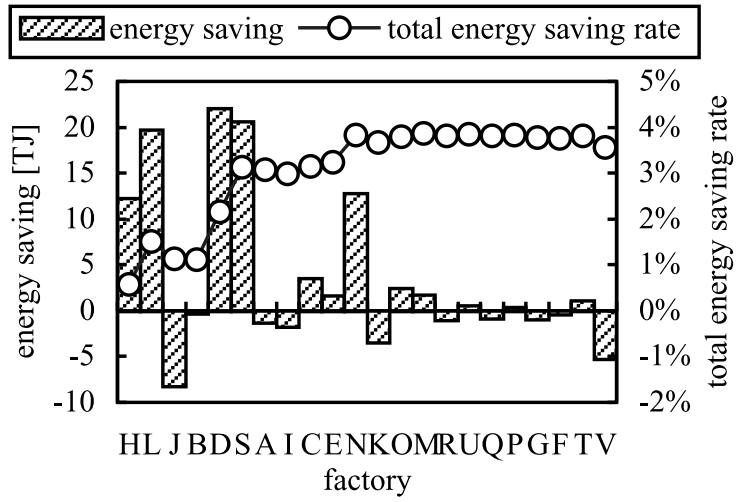

Fig. 6 Variation of energy saving in Case 3 


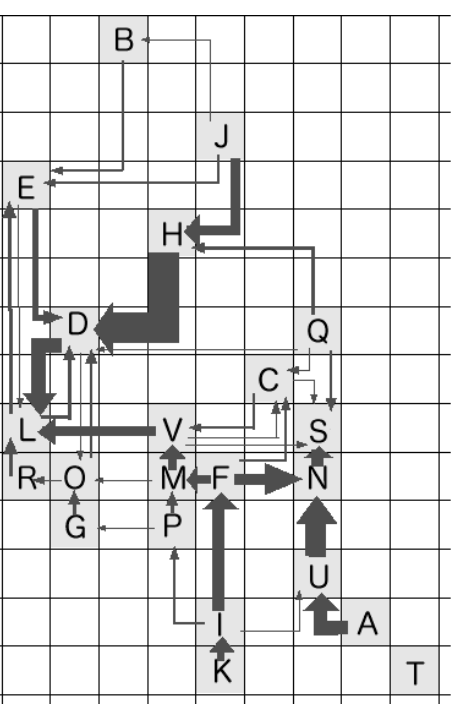

(a) Winter season

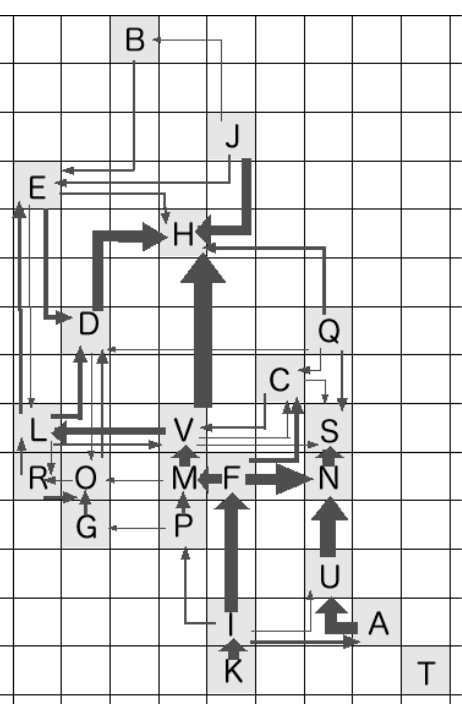

(b) Summer season

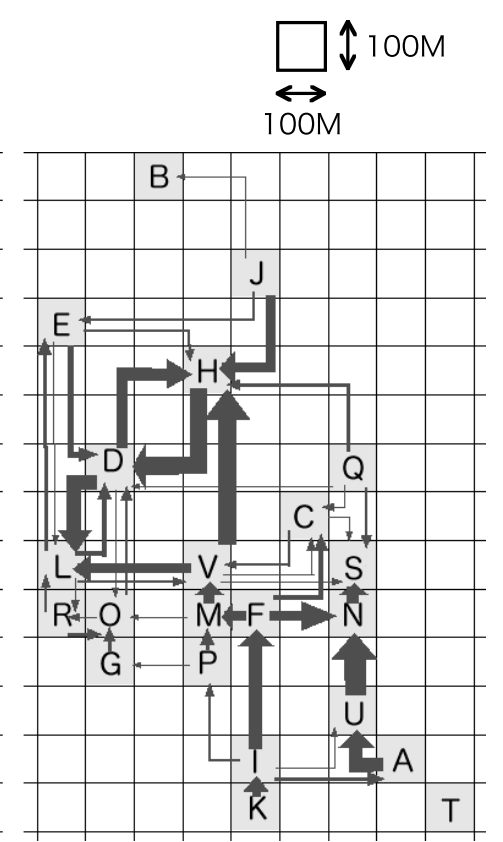

(c) Middle season

Fig. 7 Change of the steam network according to season

tory. In summer season, increasing the amount of gas turbine waste heat could increase the double-effect absorption chiller at the factory. In middle season, the steam network to another factory increases because of the decrease in the demand of both heating and cooling. Figure 8 shows steam demand and supply in winter and summer season for factory $\mathrm{H}$. Factory $\mathrm{H}$ is located at almost the center of the industrial park and has high fuel consumption, as above mentions. A gas turbine of $5,000 \mathrm{~kW}$ is introduced into factory $\mathrm{H}$. In winter season, steam from gas turbine become surplus and is transported to factories $\mathrm{D}$ and $\mathrm{L}$. On the other hand, in summer season, the steam from the gas turbine is insufficient only in factory $\mathrm{H}$ because of an increase in cooling demand. It can be seen that the energy network system could compensate the seasonal variation of energy demand during the year. Figure 9 shows the steam demand and supply of in middle season for factory D. The fuel consumption in factory $\mathrm{D}$ that is reduced by the energy network refers to Fig. 6. There was a difference in daytime and nighttime demands in factory D. The load factor of factory D is 49.5 (refer to Table 1). Steam is received from factory $\mathrm{H}$ in the daytime, and steam is transported to factory $\mathrm{H}$ at night. This demonstrates load leveling by the energy network system.

\section{Conclusion}

In this study, the author carried out optimization analysis of an energy network system based on a cogeneration system for an actual industrial park. The conclusions are as follows.

(1) The ratio of energy saving to demand reached
$22 \%$ compared with the reference system in this industrial park. This means an oil-equivalent reduction of $15,000 \mathrm{~kL}$. This result indicates the energy efficiency superiority of the cogeneration system.

(2) The introduction of a gas turbine was effective for energy saving in the energy network system, from the viewpoint of steam utilization. A gas turbine was introduced into a low thermoelectric-ratio factory, and surplus steam was transported to a high thermoelectric-ratio factory in the energy network system.

(3) The amount of steam transport changed in the middle season since there was surplus steam because of reduced air conditioning demand. It was found that the energy network system could compensate the seasonal variation of energy demand during the year as well as the daily time variation.

These simulation results are very useful for the role of the new energy demand and supply system in a zero emission industrial park for the communities of the future. To realize these systems, it is important to determine the necessary initial investment for a cogeneration system and the control of the steam pipeline route and to increase cooperation between factories. For example, Energy Service Company (ESCO) ${ }^{(14)}$ may be one of the solutions. ESCO projects can be installed with no initial capital outlay and can yield an immediate positive cash flow. The model needs further expansion; in particular, it is also effective to consider the advantage of scale of the unit price, e.g., gas turbine and fuel consumption based on nonlinear programming technique. It is important to analyze the location, the number and the scale of gas turbines 

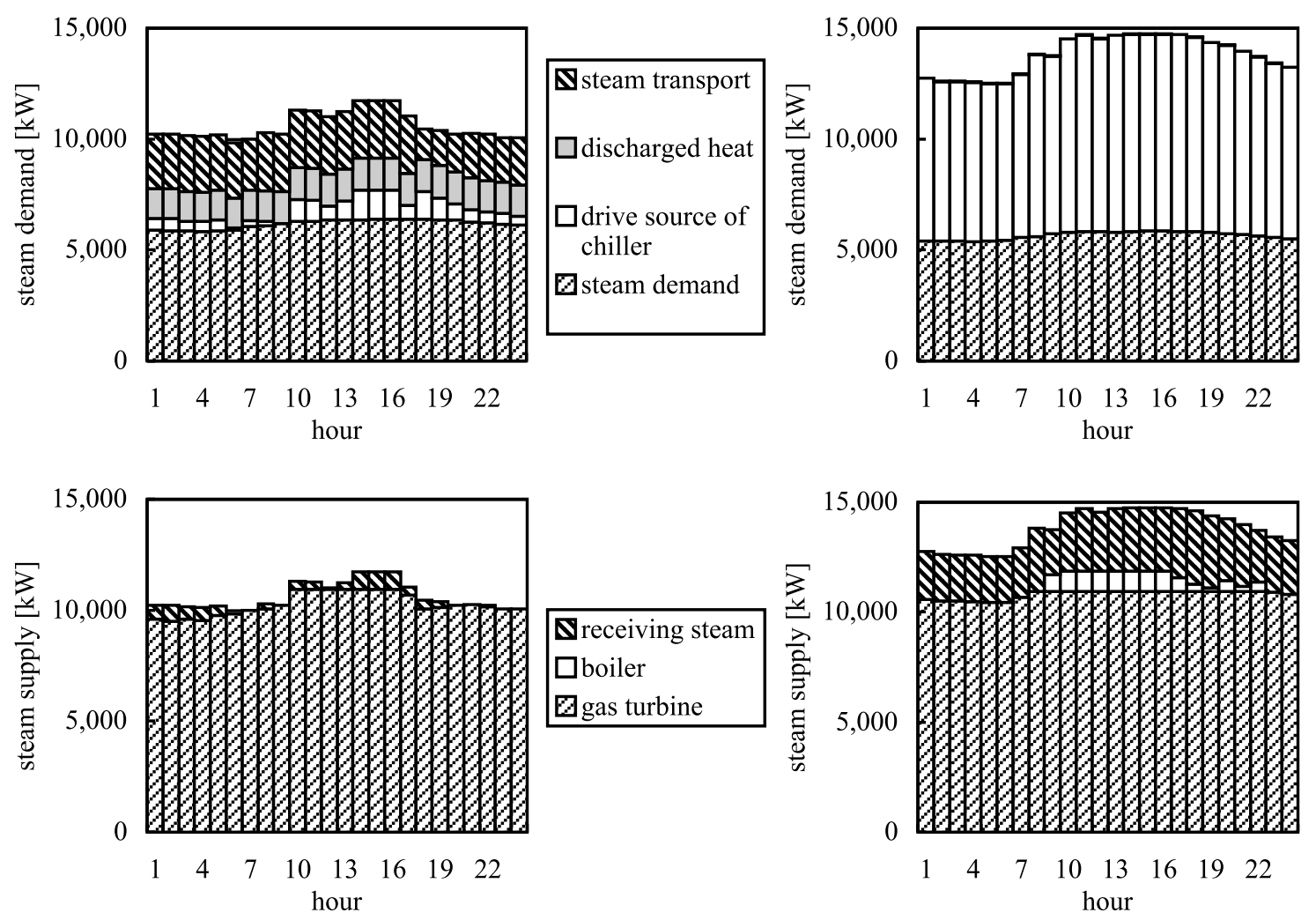

(a) Winter season

(b) Summer season

Fig. 8 Result of steam demand and supply in factory $\mathrm{H}$

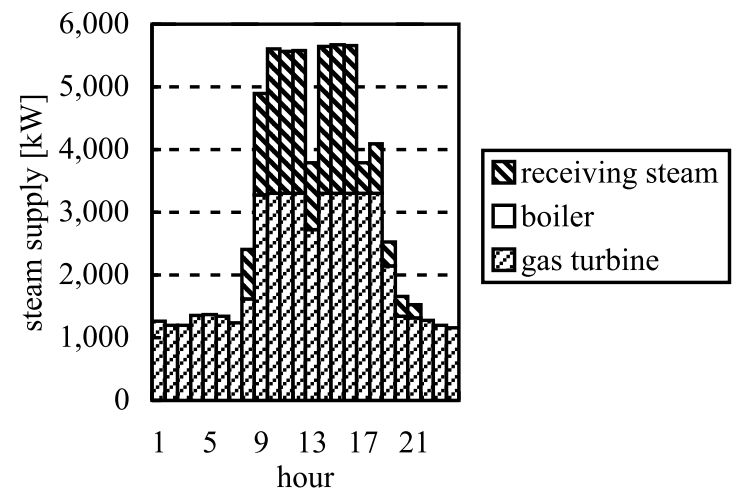

(a) Steam supply

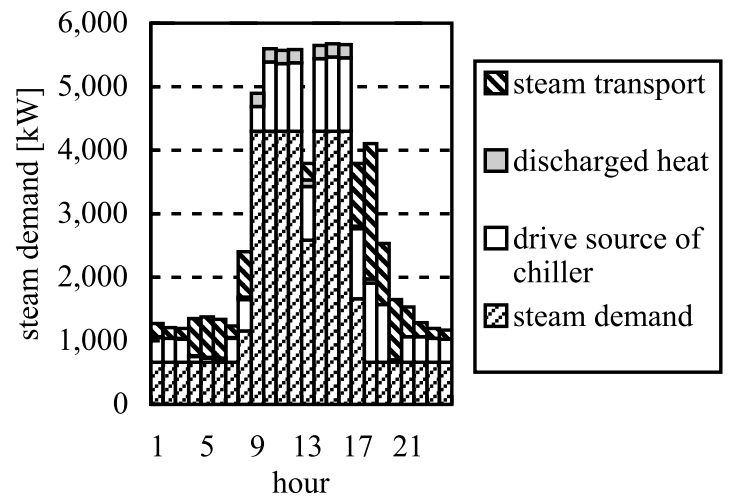

(b) Steam demand

Fig. 9 Result of steam demand and supply in middle season in factory D

when considering the introduction of multiple energy centers according to sharing among the factory. Moreover it is necessary to consider the application of a dynamic model using the MARKAL model structure ${ }^{(15)}$.

\section{Acknowledgement}

The author is grateful to the members of Kokubo Industrial Park Association. The author would like to thank the employees of the Industrial Gas Sales Department of Tokyo Gas Company Limited.

\section{References}

( 1 ) International Energy Agency, Energy Policies of IEA Countries-Japan 2003 Review, (2003), OECD.

(2) New Energy Foundation, (2005), [online]. Available: http://www.nef.or.jp/english/new/implement.html

( 3 ) Agency for Natural Resources and Energy, (2005), [online]. Available: http://www.enecho.meti.go.jp/

(4) Bruckner, T.H., Groscurth, H.M. and Kuemel, R., Competition and Synergy between Energy Technologies in Municipal Energy Systems, Energy the International Journal, Vol.22, No.10 (1997), pp.1005-1014.

( 5 ) Ishizaka, T., Yamaji, K. and Kaya, Y., Economic Evaluation of a Cogeneration System in Urban Areas with 
Variable Demand Distribution, The Transactions of the Institute of Electrical Engineers of Japan, (in Japanese), Vol.114-B, No.1 (1994), pp.505-513.

( 6 ) Shimazaki, Y., Introduction Effect of Combined Heat and Power in Inland Type Industrial Park, Proceedings of International Conference on Energy and the Environment, Shanghai, China, (2003), pp.350-355.

( 7 ) Teikoku Oil CO., LTD., (2005), [online]. Available: http://www.teikokuoil.co.jp/eteiseki/

( 8 ) Yokogawa Group, Yokogawa Group Environmental Report 2002, (2002).

(9) Morikawa, M., Eco-Industrial Developments in Japan, Indigo Development Working Paper 11, RPP International, Indigo Development Center, (2002).

(10) Shimazaki, Y., Evaluation of Refrigerating and Air Conditioning Technologies in Heat Cascading Systems under the Carbon Dioxide Emissions Constraint, Energy Policy, Vol.31, No.15 (2003), pp.1685-1697.

(11) Economic Research Association, Price Data for Construction Cost Estimating 2004 April, (in Japanese), (2004).

(12) Chiba, T., Steam, High-Temperature Water System, (in Japanese), The Energy Conservation Center, (1990).

(13) Brooke, A., Kendrick, D., Meeraus, A. and Raman, R., GAMS A User's Guide, GAMS Development Corporation, (2003).

(14) The Energy Conversion Center, (2005), [online]. Available: http://www.eccj.or.jp/esco/

(15) Sato, O., Japan's Long-Term Energy Scenarios and the Role of Nuclear Energy, Annual Meeting of the International Energy Workshop, Kyoto, Japan, (2005). 